\title{
DEVELOPMENT OF BRASSIERE SIZING SYSTEM FOR SOUTH INDIAN GIRLS
}

\section{NIRMALA VARGHESE ${ }^{1} \&$ G. THILAGAVATHI ${ }^{2}$}

${ }^{1}$ Department of Apparel \& Fashion Design, PSG College of Technology, Peelamedu, Coimbatore, Tamil Nadu, India

${ }^{2}$ Department of Textile Technology, PSG College of Technology, Peelamedu, Coimbatore, Tamil Nadu, India

\section{ABSTRACT}

Correct size and fit are the two prime issues faced by Indian women wearing brassiere. The size is different for each country. Accordingly, developing a new sizing system for brassieres for Indian girls is crucial. The present research focuses on developing a size chart specifically for unmarried girls of south India. A total of 1000 South Indian girls aged between 18-25 years were measured. Key dimensions were determined using principal component analysis. Seven best sizes were recommended and developed size chart was validated through fit analysis.

KEYWORDS: Anthropometric Survey, Size System, Size Chart, Factor Analysis, Principle Component Analysis, Fit Analysis, Brassieres

Received: Aug 07, 2020; Accepted: Aug 27, 2020; Published: Dec 02, 2020; Paper Id.: IJTFTAUG20208

\section{INTRODUCTION}

Indians can broadly be alienated to comprise at least three cluster namely people of north India, eastern India and south India. The anthropometry and body shape of the women varies as people in diverse parts of the nation follow different diet, climatic and customs. The anthropometric data is to be restructured frequently as there is a change in people's lifestyle, food habits, and cultural composition (Singh et al 2015). Mathematical models shaped to predict a variable in one population group failed to be accurate in other populations (Kautilya et al 2013). The bust dimension of women of diverse geological origin has been a topic of conjecture during the current times past (Anderson et al 2013). There are 39 ethnic groups in India with wide variety of height, body structure, stance, etc., thus the main challenge of branded apparel retail industry is correct fit of garments across Indian population.

A good quality brassiere worn by women should provide satisfying shape, fit, comfort and required support for the breast. Greenbaum et al (2003) investigated the appropriateness of brassiere fit in 102 women adverted for breast reduction surgery and found that most of the women wore a wrong size brassiere. The majority of women put on the brassiere with below sized band and outsized cup and reported that while evaluating with manufacturer's fitting rule, the measurement of back has been underestimated and the cup size has been overestimated by a mean of three sizes. Poor fit and design of brassiere causes physical and physiological problems in the body. Tight shoulder straps will exert pressure on the shoulders and rigid under wires causing pain and rashes etc. (Cherie et al 2015). Chin et al (2010) studied the physical characteristics related to brassiere fit and stated that poorly fit brassiere causes distress and effects the sales of sellers. An important feature affecting brassiere fit is the body contour. Brassiere manufacturers are not using consistent size charts and possess size chart and their own methods of grading sizes (McGhee \& Steele 2006). Manufacturing correct fitting brassieres is always been a challenging matter with producers and sellers (Wood et al., 2008). The fit issues mostly seen in brassieres are due to incorrect cup size (Oh and Chun 2014) and wearing the wrong size brassiere. Bras vary across brands from 
cup sizes to band lengths (Patel 2019).

An appropriate anthropometric data is required to build an excellent sizing system (Winks 1997). Zheng et al (2006) state that a good sizing system can be built by cautiously selecting the measuring methods to attain precise measurements, manage the subject's stance and body landmark. ISO 7250 (1996) states the procedure for measuring a live model wearing a minimum clothing and no footwear. While taking the body measurements, the model stands upright with shoulders relaxed, arms left on the sides and placing the feet together. ISO 15535 (2003) describes the common requirements to create anthropometric databases pertaining to collection of data, data base format, contents and statistical procedure.

McCulloch et al (1998) used statistical model to construct an apparel sizing system. Three features are important to create a sizing system that is having large population, decreasing the number of sizes in the system and improve the fit in the accommodated population. Hsu et al (2005) constructed a sizing system using decision tree based data mining. Decision tree based data mining technique was constructive as it allows to cover a wider range of body shapes with a few number of sizes, produce standard sizing patterns and gives a reference guide to manufacturers to carry out production easily.

According to Hsiao et al (2005), principal component analysis (PCA) is a constructive tool for providing functional representative body models. Parkinson and Reed (2009) also used PCA and linear regression statistical technique to draft details from the databases to determine values for an extensive range of body measurements. Gupta (2008) used univariate and multivariate analysis to develop the sizing system for young Indian men and women in the age group of 18-24 years. Subjective fit trials were conducted with the developed size chart and obtained good fit.

The aim of the research is to develop a new size chart for brassieres. In India, the size charts of other nations are used for construction of brassieres and the size charts referred are superseded. The current sizing system used by manufacturers are out-dated ones and there is a necessity to create a size chart targeting specific population; south India women. This will definitely lessen the fit issues in brassiere and would help them to use the right size bra. Therefore, it is imperative for clothing manufactures to have a new size chart for Indian female figure types. Study on body anatomy has recognized that as the age increases, intense changes are noticed in the female breast (Rosen 2001). Posture and bilateral symmetry of women changes as they age that affects the fit of clothing (Ashdown et al 2008). Hormonal changes in teen girls and early adult women leads to variations in body dimension and changes in breast shape. The breast profile of an unmarried woman is pointed and becomes ptotic and breast shape changes after breast feeding (Dilek et al 2010). The anthropometric survey was conducted for unmarried girls of South India. The body measurements were obtained for thousand girls in the age group of 18 -25 years. To develop a sizing system, factor analysis and cluster analysis were used using SPSS statistical software. Wear trial expressions (Physiological and Psychological fit) were carried out for validating the developed size chart.

\section{MATERIALS AND METHODS}

\subsection{Anthropometric Survey}

The new size chart was developed for brassiere using large number of breast measurements. Anthropometric survey was conducted on unmarried girls of South India in the age group 18-25. A total of 1000 girls were selected, who were pursuing their undergraduate and post graduate studies in engineering institutions and arts and science colleges in Chennai, 
Bangalore and Coimbatore. The samples consist of girls from five different states namely Tamil Nadu (39.7\%), Kerala (30.5\%), Karnataka (18.5\%), Andhra Pradesh (6.1\%) and Telangana (5.2\%).

\subsubsection{Measuring Dimensions and Measuring Points}

The body dimensions were measured on each subject as per the ISO 8559/1989 anthropometric standards. Weighing scale with the capacity up to $130 \mathrm{~kg}$ was used to measure weight and height was taken using height chart. Seven anthropometric measurements are required for brassiere and are shown in Table 1.

Table 1 Anthropometric measuring points for Brassiere

Measurements
To measure the Over bust girth, measuring tape was
taken around the circumference of the chest above the
breasts, in which tape goes under the arms and high on
the back.
To measure the Bust girth, tape was kept around the
fullest part of the breasts, typically at the nipples.
To measure the Under bust girth, tape was taken around
the midriff below the breast.




\subsubsection{Measurement Conditions}

The objectives of the research and the importance of sizing system for Indian women were explained to all the subjects. They were advised to wear any one of the branded brassiere like Lovable, Jockey and Enamor which are non-padded and are made of materials like 100\% Cotton, Cotton/Lycra and Nylon/ Polyester. Subjects were requested to wear a close fitting brassiere. The measurements were taken over the brassiere for $90 \%$ of the subjects. The subjects who were hesitant in allowing us to take the measurements over the brassiere, light weight sleeveless cotton top was provided that could be worn over the brassiere. While taking the body measurements, the brassieres that were left loose for few subjects were adjusted and kept upright. To avoid the experimental error, the type of brassiere and its fitting was ensured on all subjects before taking the measurements. The following procedures were adopted to avoid the experimental error while taking the body measurements.

- $\quad$ Look straight, stand erect and do not bend down

- Keep your shoulders relaxed

- $\quad$ Place your arms at the sides

- Keep your legs straight and knees together

- Keep the foot plane and heels placed together

- Keep length of the measuring tape parallel to the floor.

- Never flex or tense your body while you're taking measurements

\subsubsection{Trained Personnel's for Taking Body Measurements}

The positions of Brassiere measurement and methods used for measuring a Brassiere were explained to the personnel's (Luk \& Yu 2016). Five trained females were appointed to take the body measurements on the subjects. They were final year students of Textile Technology and Apparel \& Fashion Design Departments. They were well trained in a systematic manner to take accurate and consistent body measurements on the subjects. The reliability test was conducted within the five trained females using a pilot test. Twenty subjects participated in the pilot test. The trained personnel's measured the required brassiere measurements on twenty subjects. The measurements recorded by the trained personnel were compared. It was observed that the reliability between the trained people was higher and measurements error was insignificant in comparison to the differences between the trained females.

\subsection{Anthropometric Analysis of Data}

Data Collected from the anthropometric study were analysed statistically and the body measurements were correlated, classified and clustered to explain the body figure types and size of the subjects. Therefore, to build a size chart, factor analysis and cluster analysis methods were employed using SPSS statistical software.

\subsubsection{Factor Analysis}

To obtain the important factors among noticed variables, factor analysis is used. Factor analysis is used to reduce the number of variables from the data that contains many variables. Factor analysis categorizes the variables that have related characteristics. Using factor analysis, small number of factors can be derived from a higher amount of variables. Factor 
analysis consist of study on correlation coefficients of the variables with each other, factors are extracted from the correlation matrix and are rotated for the purpose of increasing the relationship between the variables.

\subsubsection{Bivariate Pearson Correlation}

The bivariate Pearson Correlation is used to measure the force and path of linear correlation between two variables. Pearson Correlation estimates if there is statistical confirmation for a linear relationship between the similar pairs of variables in the population, represented by a population correlation coefficient, $\rho$ ("rho").

\subsubsection{Clustering}

Cluster study is an examining method of data interpretation with the point of grouping objects based on their body characteristics. It is performed to understand the body dimensions of the sample. K-Means clustering using SPSS software is performed towards grouping the subjects according to similarities of measurements (Zakaria 2011). Varied figure types were recognized depending upon the clustering methods where people with related figure types were clustered together.

\subsection{Development of Size Categories}

The size categorization for Brassiere was developed based on size intervals. The sample population is classified into sections, through related subjects in each cluster other than considerably dissimilar subjects in different cluster groups. To establish the range of the different body dimensions, minimum; maximum; mean value and standard deviation for each definite set of body dimensions were calculated. Size intervals are chosen depending on the range of body dimensions and the total number of sizes obtained. Size interval was fixed depending on the best coverage of the population and not having much number of sizes.

\subsection{Sizing System Confirmation}

To confirm the sizing method developed for the sample population, the proportion of samples accommodated below every figure type and allocated size is determined. The percentage of every size was added to provide the sum percentage covered by the sizing system as a total.

\section{RESULTS AND DISCUSSIONS}

\subsection{Mathematical study of Body Dimensions}

The results of the mathematical analysis, mean and standard deviation (SD) of the anthropometric measurements of the 1000 subjects are shown in Table 2. The mean values states the figure dimensions of the "average" 18-25 years old South Indian girls. From Table 2, it is observed that among the girls aged between 18-25 years, the height of the petite girl is about $141 \mathrm{~cm}$ and the tallest girl is about $180 \mathrm{~cm}$. The average height of the girls is $157.5 \mathrm{~cm}$. The slimmest girl in the cluster weighs $35 \mathrm{~kg}$ and the stoutest girl weighs $88 \mathrm{~kg}$. The minimum and maximum bust girth of 1000 subjects is in the range of $63 \mathrm{~cm}$ to $106 \mathrm{~cm}$ and the mean bust girth is $84.5 \mathrm{~cm}$. The significant differences in the measurement between the subjects were noticed in the height, weight, under bust, bust girth and over bust areas.

Table 2: Mean and standard deviation of anthropometric measurements

\begin{tabular}{|l|l|l|l|l|}
\hline \multicolumn{1}{|c|}{ Body dimension } & \multicolumn{1}{c|}{ Minimum } & \multicolumn{1}{c|}{ Maximum } & \multicolumn{1}{c|}{ Mean } & \multicolumn{1}{c|}{ SD } \\
\hline Height $(\mathrm{cm})$ & 141.0 & 180.0 & 157.5 & 6.2 \\
\hline Weight $(\mathrm{kg})$ & 35.0 & 88.0 & 55.9 & 9.6 \\
\hline
\end{tabular}




\begin{tabular}{|l|l|l|l|l|}
\hline Under bust $(\mathrm{cm})$ & 55.8 & 101.6 & 69.9 & 7.8 \\
\hline Bust $(\mathrm{cm})$ & 63.5 & 106.0 & 84.5 & 8.1 \\
\hline Over bust $(\mathrm{cm})$ & 60.9 & 100.8 & 80.8 & 7.0 \\
\hline Strap length $(\mathrm{cm})$ & 25.4 & 36.8 & 29.4 & 1.8 \\
\hline Cup height $(\mathrm{cm})$ & 12.7 & 30.5 & 19.3 & 2.6 \\
\hline Cup width $(\mathrm{cm})$ & 14.6 & 26.4 & 20.7 & 2.3 \\
\hline Distance Between Points $(\mathrm{cm})$ & 14.0 & 24.1 & 19.0 & 1.6 \\
\hline
\end{tabular}

\subsection{Analysis of Variance (ANOVA) on Key Body Measurements}

One way Analysis of variance (ANOVA) on key body measurements between the age groups and within the age group of 18-25 years was studied using SPSS software. Table 3 shows the ANOVA test on key body measurements of brassiere at each age group. It was noticed that there is no considerable disparity in the body dimensions between age group of 18-25 years for brassiere. Statistically considerable differences were noted in the bust girth measurement between the age group with the sig. value of bust girth less than 0.05 .

Table 3: One way analysis of variance (ANOVA) for brassiere

\begin{tabular}{|c|c|c|c|c|c|c|}
\hline \multicolumn{2}{|c|}{ Body measurements } & Sum of Sq & Df & Mean Square & $\mathbf{F}$ & Sig. \\
\hline \multirow[t]{3}{*}{ Height } & Between Groups & 479.772 & 7 & 68.539 & 1.809 & .082 \\
\hline & Within Groups & 37594.672 & 992 & 37.898 & & \\
\hline & Total & 38074.444 & 999 & & & \\
\hline \multirow[t]{3}{*}{ Bust girth } & Between Groups & 1041.710 & 7 & 148.816 & 2.342 & .022 \\
\hline & Within Groups & 63020.381 & 992 & 63.529 & & \\
\hline & Total & 64062.091 & 999 & & & \\
\hline \multirow[t]{3}{*}{ Cup height } & Between Groups & 93.598 & 7 & 13.371 & 1.996 & .053 \\
\hline & Within Groups & 6645.483 & 992 & 6.699 & & \\
\hline & Total & 6739.082 & 999 & & & \\
\hline \multirow[t]{3}{*}{ Cup width } & Between Groups & 57.416 & 7 & 8.202 & 1.506 & .161 \\
\hline & Within Groups & 5401.605 & 992 & 5.445 & & \\
\hline & Total & 5459.021 & 999 & & & \\
\hline
\end{tabular}

\subsection{Body Height Distribution in Population}

To understand the height distribution of the 1000 subjects, five different height ranges like 141-148 cm, 149-156 cm, 157$164 \mathrm{~cm}, 165-172 \mathrm{~cm}$ and 173-180 cm were fixed from the minimum and maximum measurements of the body height. An interval of $7 \mathrm{~cm}$ was fixed between the size ranges. Figure 1 show, height distribution based on bust girth. It is noticed that the maximum number of subjects fall inside the stature of $160 \mathrm{~cm}$ with the bust girth of 75 to $87 \mathrm{~cm}$ (30-35 inches). It is observed that the maximum number of subjects fall in the range of $157-164 \mathrm{~cm}$ with 402 subjects, which is followed by 392 subjects in a range of $149-156 \mathrm{~cm}$. Eleven subjects were only found to be in the range of 173-180 cm. These subjects were referred as most tall in the group. 


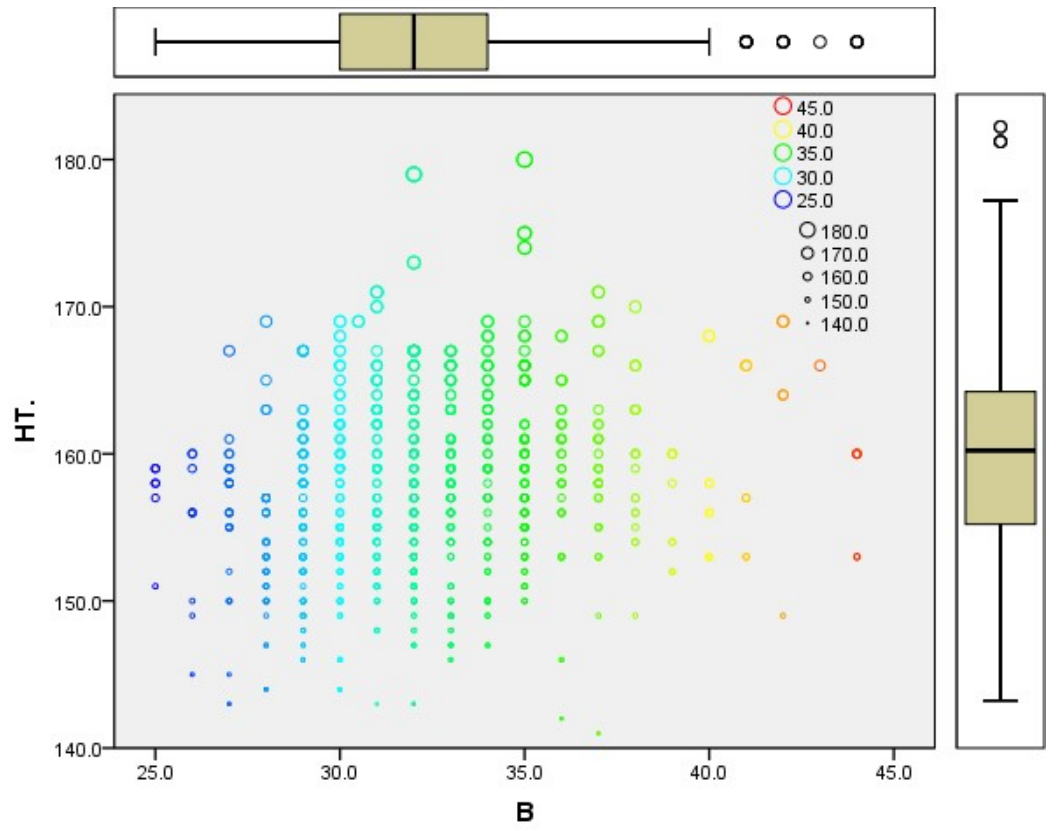

Figure 1: Height distribution (cm) based on bust girth (inch)

\subsection{Body Weight Distribution Based on Mean Bust Girth}

The distribution of body weight based on mean bust girth is shown in Figure 2. The weight range of 79-89 kg was highest with the mean bust girth size of $101.6 \mathrm{~cm}$. As the body weight increases, the bust girth also increased showing a linear trend. The lowest body weight range was $35-45 \mathrm{~kg}$ which has the smallest bust girth size of $72 \mathrm{~cm}$. It is noticed that the maximum no of subjects fall within the weight of $60 \mathrm{~kg}$ with the bust girth of 75 to $87 \mathrm{~cm}$ ( $30-35$ inches).

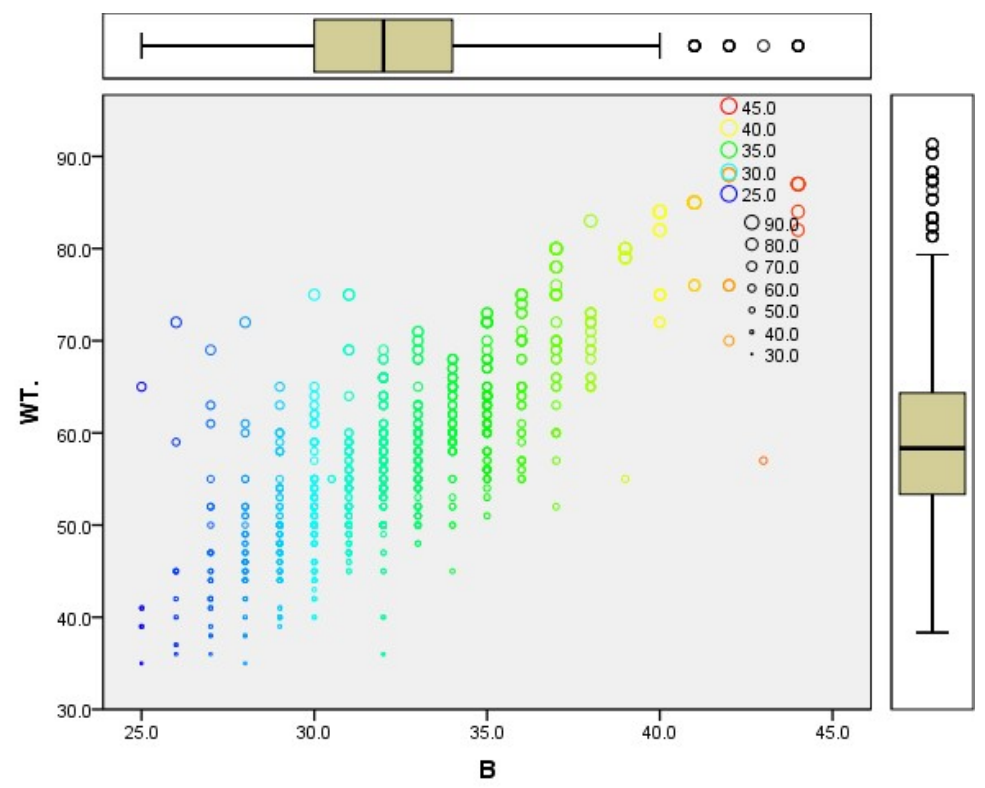

Figure 2: Distribution of body weight (kg) and bust girth (inch)

\subsection{Correlations between the Body Measurements}

In order to analyse linear relationship between the two variables statistically, the correlation between the body measurements was studied. Bivariate Pearson Correlation is used to test the linear relationship between the body 
measurements. The correlation was studied between two variables (body measurements) like body height \& body weight; body height $\&$ bust girth; body weight \& bust girth; body weight \& cup width; bust girth \& under bust girth; bust girth \& cup width.

Correlation coefficient between the body dimensions are shown in the Table 4 . The result shows that the linear relationship between the two variables were statistically significant $(\mathrm{p}<.001)$. All the variables in the cells of top right and bottom left are significantly correlated with 0.01 significance level $(p<.001$ for a two-tailed test, depending on a sample of 1000 cases). The direction of the relationship is positive and this tends to increasing for example larger height is related with larger weight. Pearson's $r$ value in body weight and bust girth is 0.849 which is close to 1 between the two variables. Pearson's $r$ value between under bust circumference and bust girth; bust circumference and cup width is 0.896 and 0.851 respectively, which is very close to 1 . This indicates that there is a powerful association among the two variables. This shows that changes in one variable are powerfully interrelated with changes in the second variable. The degree, or strength, of the relationship is moderate $(.3<|r|<.5)$. The findings of correlation analysis between body measurements identified the girth dimensions as the key body measurements for the brassiere. The correlation analysis showed that the body height has strong correlation with girth variables.

Table 4: Correlation co-efficient between body measurements

\begin{tabular}{|c|c|c|c|c|}
\hline Variables & \multicolumn{2}{|c|}{ Body weight } & \multicolumn{2}{|c|}{ Bust girth } \\
\hline \multirow{3}{*}{ Body height } & Pearson Correlation & $0.411^{* *}$ & Pearson Correlation & $0.215^{* *}$ \\
\hline & Sig. (2-tailed) & 0.000 & Sig. (2-tailed) & 0.000 \\
\hline & $\mathrm{N}$ & 1000 & $\mathrm{~N}$ & 1000 \\
\hline \multirow{4}{*}{ Body weight } & \multicolumn{2}{|l|}{ Bust girth } & \multicolumn{2}{|l|}{ Cup width } \\
\hline & Pearson Correlation & $0.849 * *$ & Pearson Correlation & $0.649 * *$ \\
\hline & Sig. (2-tailed) & 0.000 & Sig. (2-tailed) & 0.000 \\
\hline & $\mathrm{N}$ & 1000 & $\mathrm{~N}$ & 1000 \\
\hline \multirow{4}{*}{ Bust girth } & \multicolumn{2}{|l|}{ Under bust girth } & \multicolumn{2}{|l|}{ Cup width } \\
\hline & Pearson Correlation & $0.896 * *$ & Pearson Correlation & $0.851 * *$ \\
\hline & Sig. (2-tailed) & 0.000 & Sig. (2-tailed) & 0.000 \\
\hline & $\mathrm{N}$ & 1000 & $\mathrm{~N}$ & 1000 \\
\hline
\end{tabular}

\subsection{Factor Analysis}

Factor analysis was carried out on the anthropometric body measurements to establish the key body dimension that is required for brassiere. In line with Kaiser- Meyer-Olkin (KMO) criterion of adequacy (KMO) and Bartlett's test of sphericity, every examined group were appropriate for the use of Principal Component Analysis (PCA), with varimax rotation to analyse the key body dimensions. The KMO and PCA results for brassiere are shown in the Table 5.

Table 5: KMO and PCA calculation for Brassiere

\begin{tabular}{|l|l|l|l|l|l|l|l|}
\hline Garments & $\begin{array}{c}\text { Sampling } \\
\text { adequacy } \\
\text { (KMO) }\end{array}$ & $\begin{array}{c}\text { Bartlett's } \\
\text { tests }\end{array}$ & $\begin{array}{c}\text { Component } \\
\text { extracted } \\
\text { (PCA) }\end{array}$ & Factor & Eigenvalue & $\begin{array}{c}\text { Scree } \\
\text { plot }\end{array}$ & $\begin{array}{c}\text { Cumulative } \\
\%\end{array}$ \\
\hline Brassiere & 0.833 & $<0.01$ & 2 & Factor 1 & 55.79 & 2 & Compone \\
\cline { 4 - 7 } & & & Factor 2 & 14.349 & 70.139 \\
\hline
\end{tabular}


To analyse the force of the relationship between the variables, Kaiser-Meyer-Olkin (KMO) and Bartlett's test methods were used. To ensue with acceptable factor analysis, KMO should be larger than 0.5. Pair of variables that has a value less than 0.5 is discarded from the analysis. From Table 6, it is noticed that the KMO condition of adequacy is larger than 0.6 and Bartlett's test results shows less than 0.05 (Hrzenjak et al 2014). This confirms that principal component analysis can be performed on the collected data.

\subsubsection{Principal Component Analysis of Collected Anthropometric Data}

Table 6 shows the varimax rotation of component loadings in PCA of body dimensions. The result shows that, all variables in the communalities were well represented except brassiere strap measurement. The primary key component (Factor 1) corresponds to the vertical measurements. The second component (Factor 2) signifies the girth variables for brassiere. The component loadings higher than 0.7 was selected as the key dimensions under varimax rotation of factor loadings. Factor 1 and 2 was selected as the main dimensions to fragment the cluster groups for garment sizes. Eigenvalue measures the total variance related to a specific factor. The total of the Eigenvalues of PCA is equal to the summation of the variances of the data. The anthropometric measurements collected for girls shows that the Eigenvalue of Factor 2 (girth measurements) is having a value of 3.9 for brassiere. The body height shows high factor loadings in vertical body measurements. Body height is loaded at 0.976 on Factor 1 . The Factor 1 only controls $14 \%$ of the variance. It is also observed from correlation analysis that body height has a correlation of 0.215 (R2 of 0.046) with bust girth. Therefore, body height does not play a role in the sizing system. This shows that anthropometric measurements were largely dependent on girth related variables than the vertical body measurements. The key dimensions showing higher factor loadings in girth related variables are bust girth and over bust girth.

Table 6: Varimax rotation of factor loadings of body measurements

\begin{tabular}{|l|l|l|l|}
\hline \multicolumn{1}{|c|}{ Variables (cm) } & \multicolumn{1}{c|}{ Factor 1 } & Factor 2 & \multicolumn{1}{c|}{ Communalities } \\
\hline Body height & $\mathbf{0 . 9 7 6}$ & & 0.956 \\
\hline Under bust girth & & $\mathbf{0 . 8 9 2}$ & 0.816 \\
\hline Bust girth & & $\mathbf{0 . 9 4 1}$ & 0.902 \\
\hline Over bust girth & & $\mathbf{0 . 9 0 6}$ & 0.837 \\
\hline Strap length & 0.181 & & 0.062 \\
\hline Cup height & $\mathbf{0 . 7 9 1}$ & & 0.628 \\
\hline Cup width & & $\mathbf{0 . 8 4 2}$ & 0.708 \\
\hline Eigen value & 1.004 & 3.905 & \\
\hline \% of variance & 14.349 & 55.79 & \\
\hline \multirow{2}{*}{ The cumulative \% of variance } & 14.349 & 70.139 & \\
\cline { 2 - 4 } & & & \\
\hline
\end{tabular}

\subsection{Clustering}

To group the subjects in clusters, the two dimensions namely the girth variables; over bust girth and bust girth was chosen from the principal component analysis. Four groups seemed to be the best and are selected for its distinguishing personality and are sensible for clustering of female sizes (S, M, L and XL). Clusters obtained for the unmarried girls of 18-25 years and their analysis are shown in Table 7. Cluster 1 included subjects with small bust. Cluster 2 includes medium bust; cluster 3 represents large bust; Cluster 4 included extra large bust. 
Table 7: Clusters of 18-25 years old females

\begin{tabular}{|l|c|l|l|l|}
\hline \multicolumn{1}{|c|}{ Parameter } & Cluster 1 & Cluster 2 & Cluster 3 & Cluster 4 \\
\hline Mean Over bust girth, cm & 65 & 75 & 85 & 95 \\
\hline Range, cm & $60.1-70$ & $70.1-80$ & $80.1-90$ & $90.1-100$ \\
\hline Mean bust girth, cm & 68 & 78.5 & 85.5 & 99.5 \\
\hline Range, cm & $65.1-71$ & $72.1-85$ & $79.1-92$ & $93-106$ \\
\hline Number of Subjects & 84 & 319 & 371 & 98 \\
\hline Body type & Small & Medium & Large & Extra Large \\
\hline
\end{tabular}

\subsection{Development of Sizing System}

Two measurements were selected as key or sizing dimensions: bust girth and over bust girth for sizing brassiere. Bust girth and over bust girth were the determining dimensions for size in unmarried girls of 18-25 years.

\subsubsection{Determination of Size Range}

The determination of range of sizes requires differentiating the lowest and highest values (Table 1). Four body types were chosen between the ranges of values namely small, medium, large and extra large that could accommodate $100 \%$ of the sample population.

\subsubsection{Determination of Size Interval}

According to British standards BSEN 13402-3 (2004), so as to cater for dissimilarity in a nation and manufacturer's system, size interval of $4 \mathrm{~cm}$ or $8 \mathrm{~cm}$ for women is consistent for bust and waist, size interval of $4 \mathrm{~cm}$ or $6 \mathrm{~cm}$ is proposed. Kunick (1984) reports that the size interval of $8 \mathrm{~cm}$ and as low as $3 \mathrm{~cm}$ is inconsistent and suggests that the size interval of 6 $\mathrm{cm}$ is utmost consistent and mainly used by the countries.

Table 8 represents the whole distribution size of Indian unmarried girls of age 18-25 years with 10 size rolls. The range for over bust girth in the sample size is $40 \mathrm{~cm}$ from $(60-100 \mathrm{~cm})$, which is divided into four subgroups namely $60-70$ $\mathrm{cm}, 70.1-80 \mathrm{~cm}, 80.1-90 \mathrm{~cm}$ and $90.1-100 \mathrm{~cm} .10 \mathrm{~cm}$ interval is fixed between the size ranges. The size interval is selected to accommodate all body types. The total range for bust is $50 \mathrm{~cm}$ from $(65-106 \mathrm{~cm})$; the bust size range is separated into 6 sections namely $65-71.9 \mathrm{~cm}, 72-78.9 \mathrm{~cm}, 79-85.9 \mathrm{~cm}, 86-92.9 \mathrm{~cm}, 93-99.9 \mathrm{~cm}, 100-106 \mathrm{~cm}$. A size interval of $6 \mathrm{~cm}$ was used to divide the bust size range. The sizing system for brassiere is grouped based on small, medium, large and extra large that comprises of 4 sizes in all categories. For all the body type categories, six size grades of XS, S, M, L, XL and XXL are provided based on bust girth. The over bust girth ranges between $60-70 \mathrm{~cm}, 70.1-80 \mathrm{~cm}, 80.1-90 \mathrm{~cm}$ 90.1-100 $\mathrm{cm}$ with the bust girth range of $65-106 \mathrm{~cm}$. From Table 8, it is observed that the maximum accommodation is at medium and large body type.

In the small size category, one size is given (XS) with the over bust girth in the range of $60-70 \mathrm{~cm}$ and bust girth in the range of 65 to $71 \mathrm{~cm}$. Three sizes $(\mathrm{S}, \mathrm{M} \& \mathrm{~L})$ are provided in the medium and large body type $(\mathrm{M}, \mathrm{L} \& \mathrm{XL})$ with the difference in over bust girth from $70.1-80 \mathrm{~cm}$ and $80.1-90 \mathrm{~cm}$ respectively. The bust girth for medium and large body type was in the range of $72-99 \mathrm{~cm}$. The extra large body type category has three sizes (L, XL \& XXL), over bust girth ranges from $90.1-100 \mathrm{~cm}$ with bust girth between $86 \mathrm{~cm}$ and $106 \mathrm{~cm}$. A maximum of 319 subjects are in medium size and 371 subjects are in large size. Small body type has the least subjects and sizing system accommodates the population of $89.4 \%$. 
Table 8: Size Distribution for Brassiere with Over bust girth \& Bust Ranges

\begin{tabular}{|c|c|c|c|c|c|c|}
\hline \multicolumn{7}{|c|}{ BRASSIERE ANALYSIS } \\
\hline \multirow{2}{*}{$\begin{array}{l}\text { Size } \\
\text { pack }\end{array}$} & \multirow[t]{2}{*}{ Body type } & \multicolumn{3}{|c|}{ Key dimensions $\mathbf{c m}$} & \multicolumn{2}{|c|}{$\begin{array}{c}\text { Accommodation } \\
\text { rate }\end{array}$} \\
\hline & & Over bust girth & Size grade & Bust girth (cm) & $\overline{\mathbf{N}}$ & $\%$ \\
\hline 1 & Small & $60-70$ & XS & $65-71.9$ & 84 & 8.4 \\
\hline 2 & \multirow{3}{*}{ Medium } & \multirow{3}{*}{$70.1-80$} & $\mathrm{~S}$ & $72-78.9$ & 266 & 26.6 \\
\hline 3 & & & $\mathrm{M}$ & $79-85.9$ & 53 & 5.3 \\
\hline 4 & & & $\mathrm{~L}$ & $86-92.9$ & 7 & 0.7 \\
\hline 5 & \multirow{3}{*}{ Large } & \multirow{3}{*}{$80.1-90$} & $\mathrm{M}$ & $79-85.9$ & 171 & 17.1 \\
\hline 6 & & & $\mathrm{~L}$ & $86-92.9$ & 200 & 20.1 \\
\hline 7 & & & $\mathrm{XL}$ & $93-99.9$ & 15 & 1.5 \\
\hline 8 & \multirow{3}{*}{ Extra Large } & \multirow{3}{*}{$90.1-100$} & $\mathrm{~L}$ & $86-92.9$ & 6 & 0.6 \\
\hline 9 & & & $\mathrm{XL}$ & $93-99.9$ & 65 & 6.5 \\
\hline \multirow[t]{2}{*}{10} & & & XXL & $100-106$ & 27 & 2.7 \\
\hline & & & & Total & 894 & 89.4 \\
\hline
\end{tabular}

\subsection{Determination of Sizes for Constructing Brassiere}

According to Kwon et al (2009), the choice of the foremost sizes to construct garments is according to the accommodation rate. The sizes that have the accommodation rate of more than $2 \%$ are considered for developing size chart. The sizes that accommodate majority of subjects in each body type category are chosen. From Table 8, the total number of best sizes recommended for constructing brassiere for unmarried girls of 18-25 years is seven, one size (XS) in small body type category with bust girth in the range of $65-71 \mathrm{~cm}$. Two sizes $(\mathrm{S}$ and $\mathrm{M})$ in medium body type category with bust girth measuring $72-85 \mathrm{~cm}$. Two sizes ( $\mathrm{M}$ and $\mathrm{L}$ ) in large body type category with bust girth ranging from $79-92 \mathrm{~cm}$. Two sizes $(\mathrm{XL} \& \mathrm{XXL})$ in extra large body type category with bust girth in the range of $93-106 \mathrm{~cm}$.

\subsection{Development of Size Chart for constructing Brassiere}

A standard sizing is developed for Brassiere using the over bust girth and bust girth of the target population as the most influential factors for sizing Brassiere. The sizing system produced for Brassiere for unmarried girls of 18-25 years is summarized in Table 9. In view of the fact that good fit and comfort is the primary requirement of Brassiere, a new size chart is suggested for designing Brassiere for unmarried girls of 18-25 years.

Table 9: Sizes for Brassiere

\begin{tabular}{|l|l|l|l|l|l|l|l|}
\hline \multicolumn{1}{|c|}{ Size Designation } & \multicolumn{1}{c|}{ XXS } & \multicolumn{1}{c|}{ XS } & \multicolumn{1}{c|}{ S } & \multicolumn{1}{c|}{ M } & \multicolumn{1}{c|}{ L } & \multicolumn{1}{c|}{ XL } & \multicolumn{1}{c|}{ XXL } \\
\hline Over bust girth range, cm & $60-70$ & $70.1-80$ & $70.1-80$ & $80.1-90$ & $80.1-90$ & $90.1-100$ & $90.1-100$ \\
\hline Bust girth range, cm & $65-71$ & $72-78$ & $79-85$ & $79-85$ & $86-92$ & $93-99$ & $100-106$ \\
\hline Bust girth, cm & 68 & 75 & 82 & 82 & 89 & 96 & 103 \\
\hline Over bust girth & 65 & 74 & 76 & 85 & 85 & 94 & 96 \\
\hline Under bust girth & 58 & 65 & 70 & 70 & 75 & 80 & 85 \\
\hline Cup height & 12 & 14 & 16 & 18 & 19 & 21 & 24 \\
\hline Cup width & 14 & 16 & 18 & 20 & 22 & 24 & 26 \\
\hline Accommodation, \% & 8.0 & 26.6 & 5.3 & 17.1 & 20.1 & 6.5 & 2.7 \\
\hline
\end{tabular}

There are seven new sizes for brassiere to accommodate those with over bust girth between $60-100 \mathrm{~cm}$ and with bust girth from $65-106 \mathrm{~cm}$. Two very small; one small, medium, large and two extra large are recommended for brassiere. 
It shows the designated size - size XS, that refer to women by a body type of very small bust with the over bust girth range of $70-80 \mathrm{~cm}$ in a size grade of small size and bust girth of $72-78 \mathrm{~cm}$.

\subsection{Substantiation of Size Chart for Brassiere}

\subsubsection{Pattern Design and Construction of Brassieres}

Patterns were drafted for Brassieres for all seven sizes using the developed size chart and garments were constructed using cotton elastane stretch knitted fabric ( $92 \%$ cotton and $8 \%$ lycra). The components consist of bra cups, centre panel (bridge), bra elastic band, bra sides (bra wings), bra elastic straps and hooks. Seven Brassieres were constructed for the fit trial session. The fit session was carried out with live models. Three subjects from each size category participated in the fit session. The key dimensions over bust girth and bust girth were measured to find out the correct size of the subjects for the fit trial for Brassiere. Twenty one subjects who met the right size were selected for the fit trials, three subjects in each size. As the subjects were diffident in participating for brassiere fit assessment. The subjects wore the garment (kurti- light colored, translucent cotton) over the constructed new size brassier for the subjective fit trial assessment to avoid discomfit.

\subsubsection{Fit assessment of Brassieres}

Wearers perceived fit evaluation was carried out to judge the fit of the garment. Responses towards the perceived comfort and fit of brassiere were obtained from the subjects for nine aspects. Table 10 shows the questions for subjective fit assessment on brassieres. Ahead of the subjective trial fit session, the subjects were explained regarding the objective of the research and fit evaluation scales. The brassiere straps were adjusted for each subject as they wore the brassiere to achieve the best and comfortable fit. The subjects who participated in wear trial testing wore bra sizes of $28 \mathrm{~A}, 30 \mathrm{~A}, 30 \mathrm{~B}$, $30 \mathrm{C}, 32 \mathrm{~B}, 32 \mathrm{C}, 32 \mathrm{D}, 34 \mathrm{~B}, 34 \mathrm{C}, 34 \mathrm{D}, 36 \mathrm{~B}, 36 \mathrm{C}, 36 \mathrm{D}, 40 \mathrm{~B}, 40 \mathrm{C}$ and $40 \mathrm{D}$. It was noticed that $50 \%$ of subjects wore wrong size brassiere. It was wrongly selected and underestimated by women. Most of the women were not able to precisely select the right size bra. Women wore bra that are too small in the cup. Few women reported that they struggle to get good fitted bras as they have lack of knowledge on bra cup size and have not even once got professionally measured for bra size.

A total of 10 fit trial sessions were performed over a month. Two to three subjects participated in each session. The total time given for the fit trial session was 45 minutes. The subjects were requested to carry out a range of dynamic movements while wearing the garment. The subjects' perceptions of clothing fit were determined after 25 minutes and the completion of the survey by each subject was obtained after 45 minutes (Shin 2013). Ten subjects (one subject from each size category) wore the brassiere for 8 hours and their perceived fit evaluation was obtained.

Table 10: Questions on Wearer's Perceived Fit Evaluation for Brassieres

\begin{tabular}{|l|l|}
\hline SI.No. & \\
\hline 1 & The bra cup is not too tight \\
\hline 2 & The under band is not too tight \\
\hline 3 & The breast are fully contained within the cups \\
\hline 4 & The back band fits well at the back \\
\hline 5 & Straps are not too tight \\
\hline 6 & The garment gives freedom to breathe comfortably \\
\hline 7 & The garment is easy to put on \\
\hline 8 & The garment is easy to remove \\
\hline 9 & The garment gives comfortable and perfect fit \\
\hline
\end{tabular}




\subsubsection{Wearers perceived fit evaluation analysis}

Three subjects under each size category ( 3 subject's $\times 7$ sizes) participated in the subjective wear trial assessment. The subject's feedback received on nine questions for each size of brassiere was analysed to study the wearer's fit responses. Mean fit ratings and total scores were calculated for three subjects in each size. Rating on the scale ranges from 9 to 45 , higher rating indicated good fit in garment. The mean ratings obtained towards each parameter on wearer's fit assessment for Brassieres are shown in Table 11. Table 12 shows the mean total score and standard deviation calculated from the brassiere fit assessment.

Table 11: Mean Scores for Each Parameter Set on Wearer's Perceived Fit Evaluation ( $N=30)$

\begin{tabular}{|c|c|c|c|c|c|c|c|}
\hline \multirow{2}{*}{ Parameters } & \multicolumn{7}{|c|}{ Sizes } \\
\hline & XXS & XS & $\mathbf{S}$ & $\mathbf{M}$ & $\mathbf{L}$ & XL & XXL \\
\hline The bra cup is not too tight & 4.6 & 4.6 & 4.6 & 4.6 & 4.6 & 4.3 & 4 \\
\hline The under band is not too tight & 4 & 4.3 & 4.3 & 4.6 & 4.6 & 4.6 & 4.6 \\
\hline The breast are fully contained within the cups & 5 & 4.6 & 4.6 & 4.6 & 4.6 & 5 & 5 \\
\hline The back band fits well at the back & 5 & 4.6 & 4.6 & 4.6 & 5 & 5 & 4.6 \\
\hline Straps are not too tight & 4.3 & 4.6 & 4.6 & 4.6 & 5 & 4.3 & 4.3 \\
\hline $\begin{array}{l}\begin{array}{l}\text { The garment gives freedom to breathe } \\
\text { comfortably }\end{array} \\
\end{array}$ & 4.6 & 5 & 5 & 5 & 5 & 5 & 5 \\
\hline The garment is easy to put on & 5 & 4.6 & 5 & 4.6 & 5 & 4.6 & 4.3 \\
\hline The garment is easy to take out & 5 & 5 & 5 & 5 & 5 & 4.6 & 4.6 \\
\hline The garment gives comfortable and perfect fit & 4.6 & 5 & 5 & 4.6 & 5 & 4.6 & 4.6 \\
\hline
\end{tabular}

Table12: Mean Score and Standard Deviation of Wear Trial Fit Rating

\begin{tabular}{|l|l|l|}
\hline Sizes & $\begin{array}{l}\text { Mean } \\
\text { score }\end{array}$ & $\begin{array}{l}\text { Standard } \\
\text { deviation }\end{array}$ \\
\hline XXS & 42 & 0.81 \\
\hline XS & 42.3 & 0.47 \\
\hline S & 43 & 0.81 \\
\hline M & 43 & 1.63 \\
\hline L & 44 & 1.41 \\
\hline XL & 42 & 0.81 \\
\hline XXL & 41.3 & 0.47 \\
\hline
\end{tabular}

It is observed that all sizes obtained high fit score towards each parameter set and highest mean total score in e fit trial assessment. Comparatively lower ratings were noticed for the parameter, under band is not too tight. Subjects reported that the straps were comfortable and the underband was firm on the body and was tight. Subjects stated that by wearing the size brassieres, comfortable fit is attained and there was no constrain in the movement of the arms and the breast was totally encased within the cup and there was no bulging at the underarms. No significant differences were noted in the fit trial assessment obtained from the subjects who wore the brassiere for 8 hours. 


\section{CONCLUSIONS}

Inhabitants' living in diverse countries has unlike body sizes. It is essential for every country to have their own standard size chart owing to dissimilarity in race and lifestyle. The size chart that is used in India for the construction of brassieres belongs to other countries. Thus, a new size chart was developed for brassiere. Anthropometric survey was conducted on unmarried girls of South India in the age group 18-25. Body measurements were correlated, classified and clustered to describe the body shape and size of the subjects. Factor analysis and cluster analysis methods were employed using SPSS statistical software.

The size ranges in the developed size chart accommodated $89.4 \%$ of the girls measured. The total number of best sizes recommended for constructing brassiere for unmarried girls of 18-25 years is seven, one size (XS) in small body type category with bust girth in the range of $65-71 \mathrm{~cm}$. Two sizes (S and $\mathrm{M}$ ) in medium body type category with bust girth measuring $72-85 \mathrm{~cm}$. Two sizes ( L and XL) in large body type category with bust girth ranging from 79-92 cm. Two sizes (XL and XXL) in extra large body type category with bust girth in the range of 93-106cm. Most of the girls were within sizes XS (small), M (Medium) and L (Large) body category. To approve the fit of brassieres developed based on size chart, wearers perceived fit evaluation was carried out. The subjects were satisfied with the brassiere fit. Seven new sizes were established for brassieres for unmarried girls of South India in the age group 18-25 years. The resulted size chart of brassieres accommodates all body types and may possibly be used as a resource guide for clothing industries in India and also the brands that manufacture brassieres for south Indian girls. The developed size chart will enable the manufactures to construct improved fitting clothes according to the body type. This study suggests that additional anthropometric studies must be performed covering all age groups and regions for women in India.

\section{ACKNOWLEDGEMENT}

We wish to express our sincere thanks to N. Sandhya, Nivedhitha C., Shunmathi S., Mythili N. and Vidhushini R., students of PSG College of Technology for their support in carrying out the research.

\section{REFERENCES}

1. Singh I., Rawat S., Varte L R., Majumdar D., (2015). Workstation related anthropometric and body composition parameters of Indian women of different geographical regions. Journal of Krishna Institute of Medical Sciences University, 4(1), .38-44.

2. Kautilya V., Bodkha P., Poothanathan P., (2013). Determination of stature and sex from anthropometry of the foot among south Indians. International Journal of Review in Life Sciences 3(2), 2013, 22-26.

3. Anderson D. L. J., Chandler C. S., Mason A. B. M., Khan B. C., Lindsay E. J., Sandler M. R. and Wong G. L., (2013). Scientific analysis reveals major differences in the breast size of women in different countries, Journal of Female Health Sciences, 25, 268-292.

4. Greenbaum, A. R., Heslop, T., Morris, J., \& Dunn, K. W., (2003). An investigation of suitability of bra fit in women referred for reduction mammoplasty. British Journal of Plastic Surgery, Vol.3, No.56, .230-236.

5. Cherie Y. C. Chan, Winnie W. M. Yu, and Edward Newton, (2015). "Evaluation and Analysis of Bra Design", The Design Journal, Vol. 4 , Iss. 3, 33-40.

6. Premkumari, Ravindra Yaranal, et al. "Study on Anthropometric dimensions of women agricultural workers of Hyderabad Karnataka region." IJASR 6.3 (2016): 359-364.

7. Chin-Man Chen, Karen LaBat, and Elizabeth Bye, (2010). Physical characteristics related to bra fit, Ergonomics Vol. 53 , Iss. 
4, pp. 514-524.

8. McGhee D E., Steelew J R., (2006). How do respiratory state and measurement method affect bra size calculation? British journal of sports medicine, 40, pp-970-974.

9. Wood, K., Cameron, M. and Fitzgerald, K., (2008). Breast size, bra fit and thoracic pain in young women: a correlational study. Chiropractic \& Osteopathy, 16(1), 1-7.

10. Oh S., Chun J., (2014). New breast measurement technique and bra sizing system based on 3D body scan data. Journal of the Ergonomics Society of Korea, 33(4), 299-311.

11. Meda, Prashanthi, and T. KAMALAJA. "Assessment of Nutritional Status of Adolescent Girls of Medchal Mandal Rangareddy District." International Journal of Agricultural Science and Research (IJASR) 7.4 (2017): 731-736.

12. Patel A., October (2019). The majority of Women still wear the wrong Bra size. https://globalnews.ca/news/5985501/how-tobuy-a-bral

13. Winks JM (1997). Clothing sizes: International Standardization, The Textile Institute, International headquarters, Manchester, UK.

14. Zheng R., Yu, W., Fan, J., (2006). Breast measurement and Sizing, Innovation and Technology of Women's Intimate Apparel, CRC Press BocaRAton. Woodhead publishers, Cambridge, 28-58.

15. KADAM, ANJALI D., GK AWARI, and CN SAKHALE. "THRESHER RELATED ANTHROPOMETRIC PARAMETERS OF WOMEN AGRICULTURAL WORKERS FOR VIDARBHA REGION OF MAHARASHTRA (INDIA)." International Journal of Agricultural Science and Research (IJASR) 9.6 Dec 2019, 15-26

16. ISO 7250 (1996). Basic Human body Measurements for Technological Design. The International Organaisation for standardization.

17. ISO 15535, (2003). General requirements for establishing anthropometric databases. The international organization for standardization.

18. McCulloch C E., Paal, B., Ashdown S P., (1998). An optimization approach to Apparel Sizing. Journal of the operational Research Society, Vol. 49, No. 5 , 492-499.

19. Mrunalini, A. "Performance evaluation of head load manager to an alternative means to carry loads by rural women." International journal of Agricultural Science and Research 6.1 (2016): 263-268.

20. Chih-Hung Hsu, Moo-Jim J Wang, (2005). Using Decision tree based mining to establish a sizing system for the manufacture of garments. The international Journal of Advanced Manufacturing Technology, Vol. 26, Issue 5, 669-674.

21. Hsiao H, Whitestone J, Bradtmiller B, Whisler R, Zwiener J, Lafferty C, Kau TY, Gross M. (2005) Anthropometric criteria for the design of tractor cabs and protection frames. Ergonomics 48:323-353.

22. Parkinson M. B., Reed M. P., (2010). Creating virtual user populations by analysis of anthropometric data, International Journal of Industrial Ergonomics, Vol 40, Issue 1, 106-111.

23. BANERJEE, NEEPA, SURJANI CHATTERJEE, and SANDIPAN CHATTERJEE. "IMPACT OF INDIAN CLASSICAL BHARATNATYAM DANCING IN TERMS OF NOVEL ANTHROPOMETRIC MARKERS OF CARDIO-VASCULAR HEALTH STATUS: A STUDY IN BENGALEE ADULT FEMALES." International Journal of General Medicine and Pharmacy (IJGMP)6.4, Jun - Jul 2017; 7-16

24. Gupta D., (2008). Anthropometric Data Analysis and Garment Sizing System for Indian Population, $86^{\text {th }}$ Textile Institute 
World Conference, Hong Kong.

25. Rosen P P., (2001). Rosen's breast pathology, Lippincott Williams \& Wilkins, Philadelphia.

26. Ashdown S P., Na h., (2008). Comparison of 3-D body scan data to quantify upper body postural variation in older and younger women. Clothing and Textiles research journal 26 (4): 292-307.

27. Dilek K. A., Ahmet C. A., Erol B., Husanettin T., Oguz T., (2010). Anthropometric breast measurement: A study of 385 Turkish female students. Aesthetic Surgery Journal, Vol. 30, No. 1, 44-50.

28. Luk N., Yu W., (2016). Bra Fitting Assessment and Alteration, Advances in Women's Intimate Apparel Technology, Woodhead publishers, Cambridge, 121-129.

29. Zakaria N., (2011). Sizing System for Functional Clothing- Uniforms for School Children, Indian Journal of Fibre and Textiles Research, Vol.36, 348-357.

30. Bhubon M D., Subrata R., (2010). Age changes in the anthropometric and body composition characteristics of the Bishnupriya Manipuris of Cachar district, Assam. Advances in Bioscience and Biotechnology, 1(02), pp. 122-130.

31. Das S., Chowdhury T., Bose K., (2012). Age variations in the anthropometric and body composition characteristics among adult Bauri females of Paschi, Medinipur, West Bengal. Scholarly Journal of Scientific Research and Essay (SJSRE), Vol. 1(2), pp. 16-24.

32. Hrzenjak R., Dolezal K., Ujevic D., (2014). Sizing system for girls aged 13-20 years based on body types. Textile Research Journal, Vol 85, Issue 12, pp. 1293-1304.

33. British Standard Institution (2004) BS EN 13402-3. Size designation of clothes. Measurements and Intervals. British Standard Institution

34. Kunick, P., (1984). Modern sizing and pattern making for women's and children's garments

35. London: Phillip Kunick Publication.

36. Kwon, O., Jung, K., You, H., and Kim H., (2009). Determination of key dimensions for a glove sizing system by analyzing the relationship between hand dimensions. Applied Ergonomics, Vol 40, Issue 4, 762-766.

37. Shin E., (2013). Exploring consumers fit perceptions and satisfaction with Apparel fit in general. (Master's Thesis) Iowa state University, Ames, Iowa, USA. 